\title{
Otolith elemental and Sr isotopic composition as a natal tag for Biwa salmon Oncorhynchus masou subsp. in Lake Biwa, Japan
}

\author{
Yosuke Amano ${ }^{1, *}$, Masayuki Kuwahara ${ }^{2}$, Toshiro Takahashi ${ }^{3}$, Kotaro Shirai ${ }^{1}$, \\ Kodai Yamane ${ }^{4}$, Hiroshi Amakawa ${ }^{5}$, Tsuguo Otake ${ }^{1}$ \\ ${ }^{1}$ International Coastal Research Center, Atmosphere and Ocean Research Institute, The University of Tokyo, Kashiwanoha, \\ Kashiwa, Chiba 277-8564, Japan \\ ${ }^{2}$ Lake Biwa Museum, Oroshimo-cho, Kusatsu, Shiga 525-0001, Japan \\ ${ }^{3}$ Institute for Research on Earth Evolution (IFREE), Japan Agency for Marine-Earth Science and Technology (JAMSTEC), \\ Natsushima-cho, Yokosuka, Kanagawa 237-0061, Japan \\ ${ }^{4}$ Atmosphere and Ocean Research Institute, The University of Tokyo, Kashiwanoha, Kashiwa, Chiba 277-8564, Japan \\ ${ }^{5}$ Department of Geosciences, National Taiwan University, Roosevelt Road, Taipei 10617, Taiwan
}

\begin{abstract}
We examined the elemental and Sr isotopic composition of otoliths from Biwa salmon Oncorhynchus masou subsp., an endemic subspecies of the O. masou complex in the Lake Biwa (Japan) water system, to evaluate the usefulness of otolith chemistry as a natural tag for studying homing and migration history. Fish and water samples were collected from 5 major spawning rivers and 2 hatcheries. The elemental content relative to calcium $(\mathrm{Na} / \mathrm{Ca}, \mathrm{Mg} / \mathrm{Ca}, \mathrm{K} / \mathrm{Ca}, \mathrm{Mn} / \mathrm{Ca}$, $\mathrm{Sr} / \mathrm{Ca}$, and $\mathrm{Ba} / \mathrm{Ca}$ ) and $\mathrm{Sr}$ isotopic ratio $\left({ }^{87} \mathrm{Sr} /{ }^{86} \mathrm{Sr}\right)$ of the samples were analyzed using laser ablation inductively coupled plasma mass spectrometry and thermal ionization mass spectrometry, respectively. Significant variations in otolith and water sample chemistry were detected. We also observed significant relationships between the $\mathrm{Sr} / \mathrm{Ca}, \mathrm{Ba} / \mathrm{Ca}$, and ${ }^{87} \mathrm{Sr} /{ }^{86} \mathrm{Sr}$ ratios of otoliths and those of ambient water samples from which the fish were collected. The other elemental ratios and all elemental concentrations in the otoliths showed variations independent of water chemistry. Jackknife cross-validation using quadratic discriminant function analysis showed that otolith elemental composition could classify Biwa salmon juveniles by sampling location, with a high level of accuracy (mean 79\%). The mean accuracy increased to $89 \%$ when $\mathrm{Sr}$ isotopic ratios were combined with elemental data. This study thus demonstrated the suitability of otolith chemistry for determining fish distribution. Otolith chemistry successfully revealed the natal (hatching) locations of individual fish, facilitating further understanding of migration history and habitat use, which are essential for establishing effective fishery management strategies for this Near Threatened subspecies.
\end{abstract}

KEY WORDS: Biwa salmon · Otolith $\cdot$ Elemental composition $\cdot$ Sr isotopic ratio

\section{INTRODUCTION}

The Biwa salmon Oncorhynchus masou subsp. is endemic to the Lake Biwa water system, which is the largest freshwater lake in Japan (Furukawa 1989, Kimura 1990). It is a subspecies of the $O$.

*Email: amano@aori.u-tokyo.ac.jp masou complex (Oohara \& Okazaki 1996, Gwo et al. 2008) and is mostly distributed in the north basin of Lake Biwa, which is larger, deeper, and more mesotrophic than the much smaller south basin. This subspecies is an important commercial and recreational fisheries target. For stock conservation

(C) The authors 2013. Open Access under Creative Commons by Attribution Licence. Use, distribution and reproduction are unrestricted. Authors and original publication must be credited. 
and enhancement, juvenile hatchery-reared Biwa salmon have been released into several rivers flowing into Lake Biwa since 1883. However, in 2007, the subspecies was designated 'Near Threatened' by the Red List of the Ministry of the Environment, Japan.

The lake-type anadromous Biwa salmon migrates upstream and spawns in rivers of the Lake Biwa water system from the middle of October to early December (Oda et al. 2008a). Despite being a landlocked subspecies, these fish still show an anadromous-type behavior of migrating into rivers for spawning. The eggs hatch from late December once the cumulative water temperature reaches $407^{\circ} \mathrm{C}$ after fertilization (Fujioka 1990, Oda et al. 2008b). Larvae develop in the river, and almost all juvenile Biwa salmon migrate downstream between May and June. They typically remain in the lake for 2 to $4 \mathrm{yr}$ before they mature (Kato 1978, Fujioka 1990). Like other subspecies of the Oncorhynchus masou complex, there are alternative migratory types of Biwa salmon, including stream residents and early summer upstream migrants (Kuwahara \& Iguchi 1994, 2007). However, little is known about the migration patterns of the lake form, including whether maturing fish return to their natal stream. This is extremely important for understanding their life history strategy and for establishing effective fishery management policies for this threatened subspecies. The life history strategy of Biwa salmon has become fully adapted to the peculiar environmental settings of Lake Biwa and appears to be very different from that of the other subspecies of the $O$. masou complex. Therefore, a better understanding of the migration patterns of the lake form of this subspecies is necessary for sustainable production and conservation.

Artificial tags and genetics have been used to investigate the homing and migration patterns of salmonid fish in previous studies (Hendry et al. 2004, Horreo et al. 2012, McCraney et al. 2012). However, artificial tagging methods are often impractical because of the high mortality rate during early life stages and the requirement for a large number of individuals to be tagged to ensure the recapture of sufficient numbers. Genetic make-up can link fish to their origin population, but ecological differences among fish cannot be detected within a single genetic population.

Analysis of otolith chemical composition is often considered to be the most informative method of determining species migration at a fine spatial scale (Thorrold et al. 2001, Fodrie \& Herzka 2008). The usefulness of otolith chemical composition as a geographic tag has also been demonstrated for several fish species, such as Atlantic cod Gadus morhua (Campana et al. 1994), striped bass Morone saxatilis (Secor et al. 2001), American shad Alosa sapidissima, and black bream Acanthopagrus butcheri (Elsdon et al. 2008). Otoliths are composed of metabolically inert calcium carbonate crystals and increase in size because of daily deposition of elements, which makes them reflect environmental factors such as temperature, salinity, and elemental composition of the ambient water (Townsend et al. 1992, Fowler et al. 1995, Campana \& Thorrold 2001, Elsdon \& Gillanders 2002, Bath Martin \& Thorrold 2005, Yokouchi et al. 2011). Differences in the elemental composition of otoliths have been observed in different habitats and areas of different rivers (Thorrold et al. 1998), estuaries (Patterson et al. 2004, Yamane et al. 2010, 2012), and oceans (Ashford et al. 2005).

In addition, previous studies have shown that combined analysis of the elemental composition and isotopic ratios of otoliths can reveal environmental differences with greater precision (Walther \& Thorrold 2008a,b, Gibson-Reinemer et al. 2009). The Sr isotopic ratio $\left({ }^{87} \mathrm{Sr} /{ }^{86} \mathrm{Sr}\right)$ of fish otoliths is also known to be a powerful marker of freshwater habitats in which fish are distributed. The otolith ${ }^{87} \mathrm{Sr} /{ }^{86} \mathrm{Sr}$ ratio is consistent with the isotopic ratio of the ambient water, which reflects the age and mineralogy of the local surficial geology (Kennedy et al. 1997, 2000, Ingram \& Weber 1999, Amakawa et al. 2012). Therefore, the inherent trace element composition and isotopic ratio of otoliths enables the classification of individual fish according to differences in habitat use and migration history (Bradbury et al. 2011). Nakano et al. (2008) reported significant spatial variation in the elemental composition and ${ }^{87} \mathrm{Sr} /{ }^{86} \mathrm{Sr}$ ratio of rivers around Lake Biwa. Therefore, combined analysis of elemental and isotopic signatures should provide important information for determining the natal rivers of individual Biwa salmon.

To evaluate the use of otolith chemistry as a natural tag for determining the natal habitat of Biwa salmon, we examined the elemental and $\mathrm{Sr}$ isotopic signatures of the otoliths of juveniles collected from several rivers and hatcheries around Lake Biwa, and compared these data with the elemental composition and isotopic ratios of ambient waters. We demonstrated that analysis of otolith chemical signatures can be used to investigate the homing and migration history of individual Biwa salmon, a subspecies of the Oncorhynchus masou complex endemic to Lake Biwa. 


\section{MATERIALS AND METHODS}

\section{Fish collection}

The number of Biwa salmon that migrate upstream to spawn in the rivers flowing into the north basin is much greater than the number of migrants in the rivers of the south basin (Fujioka 1990, Oda et al. 2011). The juvenile Biwa salmon used in the present study were thus collected from 5 rivers around the north basin where more fish of this subspecies migrate upstream. In total, 129 wild and 52 hatcheryreared juveniles were collected from 5 rivers and 2 hatcheries in the Lake Biwa water system, respectively (Fig. 1, Table 1). Wild fish were collected using an electric shocker (Smith-Root) from each river in early March 2010 prior to their downstream migration to the lake. Hatchery fish were reared in underground water in each hatchery for about 6 mo from early October 2009 and were collected in late March 2010 immediately before their planned release into the rivers. The total length (TL; Table 1) of each fish was measured, and the fish were then frozen until otolith chemical analysis could be performed in the laboratory.

\section{Water sample collection}

Water samples were collected from the same locations as the juvenile Biwa salmon (Fig. 1, Table 1). Samples were collected along the main stem of each river; at the hatcheries, water samples were collected from each hatchery pond. Collections were made be-

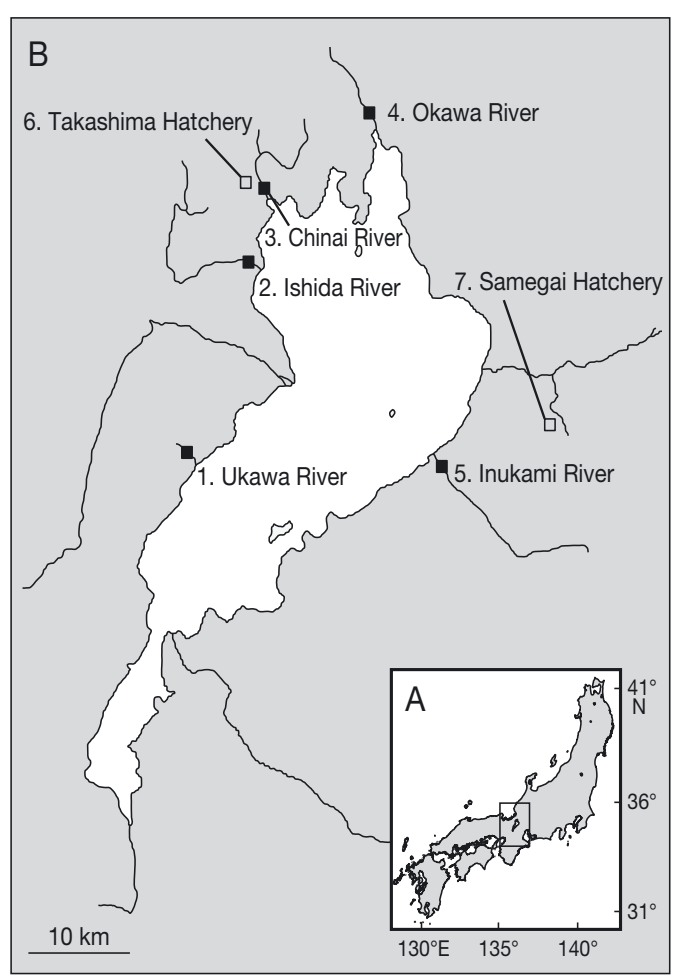

Fig. 1. Lake Biwa, Japan, and the sampling areas for Biwa salmon Oncorhynchus masou subsp. (A) Location of Lake Biwa in central Japan. (B) Study area showing the 7 sampling locations; $\mathbf{\square}$ : wild river, $\square$ : hatchery

tween November 2009 and April 2010, which corresponded to the period covering the spawning to juvenile stage of Biwa salmon. Water temperature was measured at the time of collection. One liter of water was collected for analysis of the elemental composition

Table 1. Oncorhynchus masou subsp. Sampling location, average total length (TL), otolith diameter, and sample size (n) of juvenile Biwa salmon for each analysis and water temperature at each sampling site. R: river; H: hatchery

\begin{tabular}{|c|c|c|c|c|c|c|c|c|c|}
\hline & \multirow[t]{2}{*}{ Location } & \multirow[t]{2}{*}{ Code } & \multirow{2}{*}{$\begin{array}{c}\mathrm{TL} \\
(\mathrm{mm})\end{array}$} & \multirow{2}{*}{$\begin{array}{l}\text { Otolith diam. } \\
\qquad(\mu \mathrm{m})\end{array}$} & \multirow{2}{*}{$\begin{array}{c}{ }^{87} \mathrm{Sr} /{ }^{86} \mathrm{Sr} \\
\text { (n) }\end{array}$} & \multirow{2}{*}{$\begin{array}{l}\text { Element } \\
\text { (n) }\end{array}$} & \multicolumn{3}{|c|}{ Water temperature $\left({ }^{\circ} \mathrm{C}\right)$} \\
\hline & & & & & & & Nov 2009 & Mar 2010 & Apr 2010 \\
\hline \multirow[t]{2}{*}{1} & Ukawa R & UKW & $36.7 \pm 2.6$ & $336 \pm 39.6$ & 6 & - & 13.2 & 8.2 & 9.0 \\
\hline & & & $36.0 \pm 3.0$ & $333 \pm 34.3$ & - & 20 & & & \\
\hline \multirow[t]{2}{*}{2} & Ishida R & ISD & $35.0 \pm 2.0$ & $350 \pm 28.0$ & 6 & - & 11.6 & 7.6 & 10.7 \\
\hline & & & $35.5 \pm 2.0$ & $353 \pm 25.4$ & - & 20 & & & \\
\hline \multirow[t]{2}{*}{3} & Chinai R & $\mathrm{CHN}$ & $36.0 \pm 4.3$ & $335 \pm 36.7$ & 5 & - & 12.5 & 8.0 & 10.7 \\
\hline & & & $35.8 \pm 3.2$ & $324 \pm 27.0$ & - & 20 & & & \\
\hline \multirow[t]{2}{*}{4} & Okawa R & OKW & $35.5 \pm 0.5$ & $346 \pm 20.0$ & 6 & - & 14.8 & 9.1 & 10.8 \\
\hline & & & $35.3 \pm 1.3$ & $340 \pm 18.8$ & - & 20 & & & \\
\hline \multirow[t]{2}{*}{5} & Inukami R & INK & $38.1 \pm 5.3$ & $361 \pm 41.9$ & 6 & - & 15.2 & 12.1 & 14.8 \\
\hline & & & $36.7 \pm 3.9$ & $349 \pm 32.4$ & - & 20 & & & \\
\hline \multirow[t]{2}{*}{6} & Takashima H & TKS & $52.8 \pm 5.8$ & $561 \pm 61.4$ & 6 & - & 13.5 & 14.0 & - \\
\hline & & & $50.5 \pm 8.2$ & $546 \pm 53.7$ & - & 20 & & & \\
\hline \multirow[t]{2}{*}{7} & Samegai H & SMG & $61.3 \pm 4.2$ & $572 \pm 38.7$ & 6 & - & 12.1 & 12.2 & 12.4 \\
\hline & & & $61.6 \pm 5.6$ & $574 \pm 36.7$ & - & 20 & & & \\
\hline
\end{tabular}


and $\mathrm{Sr}$ isotopic ratio. The water was filtered through $0.45 \mu \mathrm{m}$ membrane filters (ADVANTEC ${ }^{\circledR}$ ), stored in acid-washed polypropylene bottles, and acidified (1\%) using concentrated ultrapure $\mathrm{HCl}$ (Tamapure-AA100, Tama Chemicals). All glass filtration materials used for sample collection were acid-washed prior to use.

\section{Otolith multi-elemental analysis using laser ablation ICP-MS}

Both sagittal otoliths were extracted from each thawed fish. They were cleaned and rinsed with Milli-Q water, air-dried, and then kept in a clean plastic case until analysis. To determine the elemental composition, the otolith from the left side was embedded in epoxy resin (Epofix, Struers), mounted on a glass slide, and ground to the core using a grinding machine equipped with a diamond cup wheel (Discoplan-TS, Struers). It was then polished further with a colloidal silica suspension on an automated polishing wheel equipped with a semi-automatic specimen mover (Planopol-V equipped with PdMForce, Struers). Finally, it was cleaned for $10 \mathrm{~min}$ in an ultrasonic bath, rinsed several times in Milli-Q water, and then air-dried.

We analyzed the elemental composition of 20 otoliths per sampling site (Table 1). Seven isotopes $\left({ }^{23} \mathrm{Na},{ }^{25} \mathrm{Mg},{ }^{39} \mathrm{~K},{ }^{43} \mathrm{Ca},{ }^{55} \mathrm{Mn},{ }^{88} \mathrm{Sr},{ }^{138} \mathrm{Ba}\right)$ were measured in each otolith by laser ablation ICP-MS, which coupled a $213 \mathrm{~nm}$ Nd-YAG laser ablation system (New Wave Research) to ICP-MS (7500CS, Agilent). Each otolith was ablated by continuously moving the laser beam (diameter: $65 \mu \mathrm{m}$ ) from one edge to the opposite edge through the core at a speed of $5 \mathrm{\mu m} \mathrm{s}^{-1}$. The laser beam diameter was large enough to cover the otolith core area with a diameter of about $10 \mu \mathrm{m}$. This scanning area covered a substantial portion of the juvenile otolith and represented approximately 1 to $3 \mathrm{mo}$ of early life. Elemental composition was determined according to the methods of Yamane et al. $(2010,2012)$. To improve the accuracy of the measurements, we used both helium flushing and a stabilizer device (Tunheng \& Hirata 2004). The elemental data for each otolith are presented as the average of the scanning line. The frequency of the laser beam was $10 \mathrm{~Hz}$. Background levels and standards were examined before and after each scan. The isotope ${ }^{43} \mathrm{Ca}$ was used as an internal standard, and all elemental data are expressed in terms of their molar ratio relative to calcium. To smooth the data along the scanning lines, the elemental ratio relative to calcium was averaged using a 5-point running mean. The detection limits (in $\mu \mathrm{mol} \mathrm{mol}{ }^{-1}$ ) achieved in this study were 101.7 for $\mathrm{Na} / \mathrm{Ca}, 0.74$ for $\mathrm{Mg} / \mathrm{Ca}$, 10.8 for $\mathrm{K} / \mathrm{Ca}, 0.50$ for $\mathrm{Mn} / \mathrm{Ca}, 0.03$ for $\mathrm{Sr} / \mathrm{Ca}$, and 0.001 for $\mathrm{Ba} / \mathrm{Ca}$. These values were calculated on the basis of 3 standard deviations from the mean blank count of each isotope. The content of each element was above the limit of detection for all samples. Calibration from the signal intensity to the element was performed using 3 standard materials, including NIST SRM 612 standard glass distributed by the National Institute of Standards and Technology (NIST), USA, and pressed pellets of certified reference material of powdered coral (JCp-1) and powdered giant clam (JCt-1) distributed by the National Institute of Advanced Industrial Science and Technology (AIST), Japan (Shirai et al. 2008). The standard used in each analysis was chosen according to the elemental composition of each standard material. Mean estimates of precision $(\%$, relative standard deviation) based on the JCp-1 standard were 2.86 for $\mathrm{Na} / \mathrm{Ca}, 2.94$ for $\mathrm{Mg} / \mathrm{Ca}, 9.67$ for $\mathrm{K} / \mathrm{Ca}, 8.92$ for $\mathrm{Mn} / \mathrm{Ca}, 2.35$ for $\mathrm{Sr} / \mathrm{Ca}$, and 5.85 for $\mathrm{Ba} / \mathrm{Ca}$.

\section{Otolith Sr isotopic analysis using TIMS}

Five or 6 otoliths obtained from fish at each sampling location were used for $\mathrm{Sr}$ isotopic analysis (Table 1). Chemical separation and thermal-ionization mass spectrometry (TIMS) for Sr isotopic analysis were performed as described by Takahashi et al. (2006, 2009). Briefly, each whole otolith was dissolved in $7 \mathrm{M} \mathrm{HNO}_{3}$ (Tamapure-AA-100, Tama Chemicals) in a PTFE beaker. Sr in the dissolved sample was then purified by ion chromatography using Sr-spec resin (Eichrom Technologies). Sr isotopic analysis was conducted on TIMS (TRITON TI, Thermo Finnigan) at the Japan Agency for Marine-Earth Science and Technology (JAMSTEC), Japan. The ${ }^{87} \mathrm{Sr} /{ }^{86} \mathrm{Sr}$ ratio was normalized for isotopic fractionation using a correction to ${ }^{88} \mathrm{Sr} /{ }^{86} \mathrm{Sr}$ of 8.375209 . The NIST SRM 987 standard value was $0.710253 \pm 0.000011(2 \sigma, \mathrm{n}=$ 16). The ${ }^{87} \mathrm{Sr} /{ }^{86} \mathrm{Sr}$ ratio of all data was corrected for instrumental drift and bias using a correction to the NIST SRM 987 standard of 0.710245 for each daily data set.

\section{Elemental composition of water determined by ICP-MS}

The elemental composition of water samples $\left({ }^{23} \mathrm{Na}\right.$, ${ }^{25} \mathrm{Mg},{ }^{39} \mathrm{~K},{ }^{43} \mathrm{Ca},{ }^{55} \mathrm{Mn},{ }^{88} \mathrm{Sr},{ }^{138} \mathrm{Ba}$ ) was measured by 
solution-based ICP-MS (Table 1). These elements were chosen on the basis of their detection limits, which were calculated based on 3 standard deviations from the mean blank ( $\mathrm{HNO}_{3}$ background) count of each isotope. The values (in $\mathrm{mg} \mathrm{l}^{-1}$ ) were 57.19 for ${ }^{23} \mathrm{Na}, 4.83$ for ${ }^{25} \mathrm{Mg}$, 8.77 for ${ }^{39} \mathrm{~K}, 56.96$ for ${ }^{43} \mathrm{Ca}, 0.03$ for ${ }^{55} \mathrm{Mn}, 0.11$ for ${ }^{88} \mathrm{Sr}$, and 0.04 for ${ }^{138} \mathrm{Ba}$. All analytical procedures were performed according to Yamane et al. (2012). Calibration from the signal intensity to the element was performed using 3 liquid standards, including JSAC 0301-3 and JSAC 0302-3 distributed by the Japan Society for Analytical Chemistry, and ICP Multi Element Standard Solution X distributed by Merck Chemicals. Liquid standards and instrument blanks of $1 \% \mathrm{HNO}_{3}$ were analyzed for every 8 samples. Beryllium, scandium, indium, and bismuth were added to all samples and standard solutions (to $4.5 \mu \mathrm{g} \mathrm{l}^{-1}$ ) as an internal standard to correct for instrumental drift. An internal laboratory river water standard was used to assess measurement reproducibility. Mean estimates of reproducibility (\%, relative standard deviation) were 3.51 for $\mathrm{Na} / \mathrm{Ca}$, 3.62 for $\mathrm{Mg} / \mathrm{Ca}, 1.42$ for $\mathrm{K} / \mathrm{Ca}, 3.44$ for $\mathrm{Mn} / \mathrm{Ca}, 4.45$ for $\mathrm{Sr} / \mathrm{Ca}$, and 3.99 for $\mathrm{Ba} / \mathrm{Ca}$.

\section{Sr isotope analysis of water using TIMS}

Prior to the analysis of the ${ }^{87} \mathrm{Sr} /{ }^{86} \mathrm{Sr}$ ratio in the sample water, $980 \mathrm{ml}$ of each sample was dried out in a Teflon bottle on a hot plate at $90^{\circ} \mathrm{C}$, and the residue was then dissolved with $0.5 \mathrm{ml}$ of $7 \mathrm{M} \mathrm{HNO}_{3}$ (Tamapure-AA-100, Tama Chemicals). Chemical separation and mass spectrometry for Sr were performed using the same protocols as those for otolith samples (Takahashi et al. 2006, 2009). During water sample measurement, the NIST SRM 987 value was 0.710245 $\pm 0.000014(2 \sigma, \mathrm{n}=16)$.

\section{Statistical analyses}

Otolith data for each elemental and isotopic ratio were examined to determine their normality and homogeneity of variance using either a Shapiro-Wilk normality test $(\alpha=0.05)$ or Bartlett's test $(\alpha=0.05)$. To meet the model assumptions, the data were transformed into natural log values if necessary. Normality was confirmed for all data. However, heterogeneity of variance remained for all otolith elemental and isotopic ratios after transformation. We therefore used nonparametric methods such as the KruskalWallis and Steel-Dwass tests to examine the chemi- cal differences among the 7 sampling locations. We also examined correlations between otolith and water chemistry findings. Correlations were fitted to plots of mean otolith against mean water ratios and concentrations for all chemical compositions. Mean values were used because individual otoliths and water samples were not paired. To examine the ability of otolith chemistry to discriminate between habitant differences, we used quadratic discriminant function analysis (QDFA) of multi-signatures for each sampling group, as QDFA does not assume homogeneity of covariance matrices. To quantitate the number of otolith analyses, the number of Sr isotope data points was simulated as 20 for each sampling group with a normal distribution random number algorithm based on the mean otolith ratios and standard errors according to Walther \& Thorrold (2008b). We tested the ability of otolith chemical composition to discriminate habitat differences using QDFA with jackknife cross-validation.

\section{RESULTS}

Considerable differences were observed in the elemental composition of the water samples at each sampling location (Fig. 2). Concentrations of $\mathrm{Na}, \mathrm{K}$, and $\mathrm{Ba}$ were relatively high in the Inukami River (INK), and those of $\mathrm{Mg}$ and $\mathrm{Sr}$ were high in the Samegai Hatchery (SMG; Fig. 2). Mn concentration was high in the Chinai River (CHN) and Okawa River (OKW). Lower concentrations of $\mathrm{Mg}, \mathrm{Mn}, \mathrm{Sr}$, and Ba were observed in the Ukawa River (UKW). INK, Takashima Hatchery (TKS), and SMG had considerably low concentrations of $\mathrm{Mn}$. Na and K concentrations were relatively low in SMG. The concentration of each element relative to calcium also varied among sampling locations (Fig. 2). All elemental ratios were considerably low in SMG. Na/Ca and $\mathrm{K} / \mathrm{Ca}$ were high in UKW, and $\mathrm{Sr} / \mathrm{Ca}$ and $\mathrm{Ba} / \mathrm{Ca}$ were high in the Ishida River (ISD). The water Sr isotope ratio was relatively high in ISD and TKS and low in SMG (Fig. 3).

Otolith elemental composition and ${ }^{87} \mathrm{Sr} /{ }^{86} \mathrm{Sr}$ ratios of Biwa salmon thus varied significantly among the sampling locations (Kruskal-Wallis test, $\mathrm{p}<0.001$; Fig. 4). Steel-Dwass tests revealed significant differences in the $\mathrm{Na} / \mathrm{Ca}, \mathrm{Mg} / \mathrm{Ca}, \mathrm{Sr} / \mathrm{Ca}$, and $\mathrm{Ba} / \mathrm{Ca}$ of otoliths across sampling locations $(p<0.001)$. The otolith $\mathrm{Na} / \mathrm{Ca}$ of UKW fish and the $\mathrm{Mg} / \mathrm{Ca}$ of TKS and SMG fish were markedly low compared to those of fish from other sampling locations. The otolith Sr/Ca was considerably higher in ISD and TKS fish and 

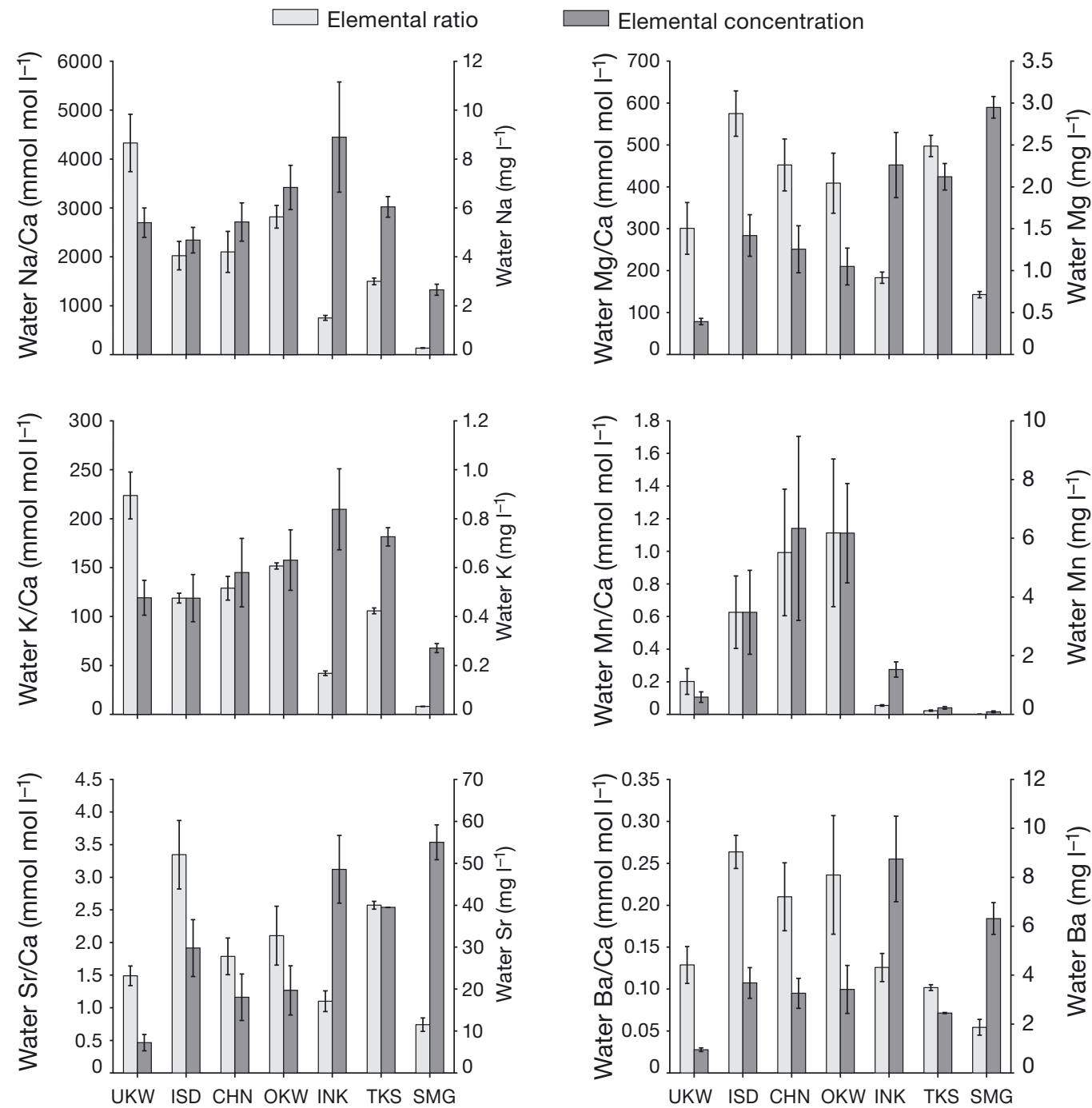

Fig. 2. Elemental ratios and concentrations (mean \pm analytical error) in water taken from the sampling locations. Location codes are shown in Table 1

lower in INK and SMG fish. A lower otolith $\mathrm{Ba} / \mathrm{Ca}$ was also observed in TKS fish. The otolith ${ }^{87} \mathrm{Sr} /{ }^{86} \mathrm{Sr}$ ratio was also significantly higher in ISD fish and lower in SMG fish, which corresponds with the water sample findings (Fig. 2).

We found significant relationships between otolith and ambient water $\mathrm{Sr} / \mathrm{Ca}, \mathrm{Ba} / \mathrm{Ca}$, and ${ }^{87} \mathrm{Sr} /{ }^{86} \mathrm{Sr}$ ratios, with strong correlations (Sr/Ca: $\mathrm{r}^{2}=0.88, \mathrm{p}<0.05$; $\mathrm{Ba} / \mathrm{Ca}: \mathrm{r}^{2}=0.65, \mathrm{p}<0.05 ;{ }^{87} \mathrm{Sr} /{ }^{86} \mathrm{Sr}: \mathrm{r}^{2}=0.95, \mathrm{p}<0.05$; Fig. 5). There were no significant relationships between the remaining elemental ratios in the otoliths and ambient water relative to calcium $(\mathrm{Na} / \mathrm{Ca}, \mathrm{Mg} /$ $\mathrm{Ca}, \mathrm{K} / \mathrm{Ca}$, and $\mathrm{Mn} / \mathrm{Ca}_{i} \mathrm{r}^{2}=0.002-0.39, \mathrm{p}=0.13-0.92$; Fig. 5). Likewise, no significant relationships were found between the elemental ratios of the otoliths and the elemental concentrations in the ambient water $\left(r^{2}=0.01-0.21, p=0.30-0.81\right)$.

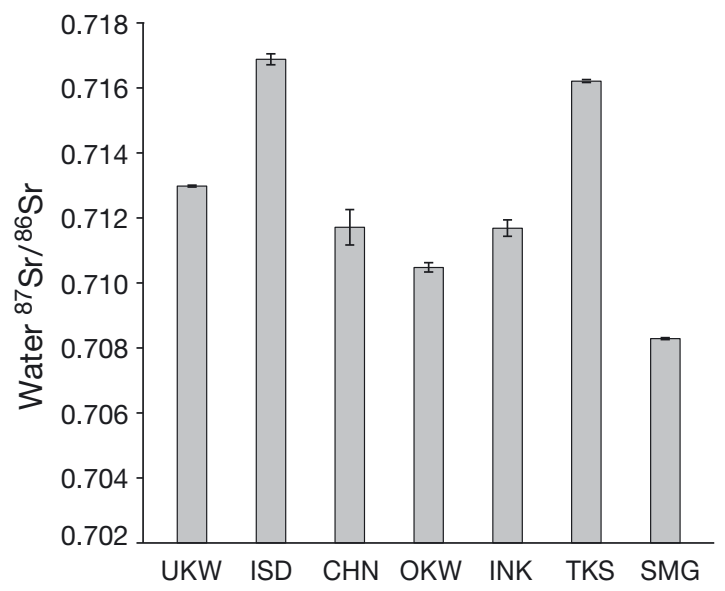

Fig. 3. Sr isotopic ratio (mean \pm analytical error) of water samples from the sampling locations. Location codes are shown in Table 1 


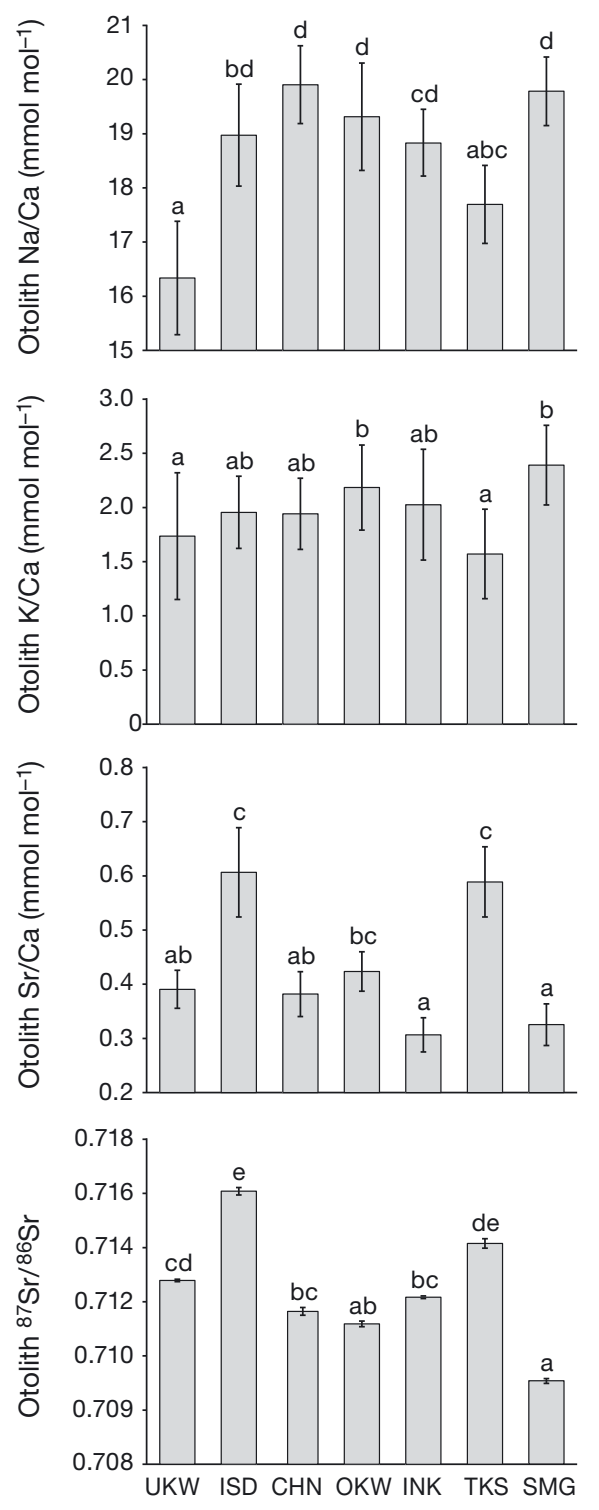

QDFA of the elemental data from otoliths indicated that the classification accuracy ranged from 60 to $100 \%$ with a mean of $79 \%$ per sampling location (Table 2). The highest and lowest classification accuracies were for TKS $(100 \%)$ and CHN (65\%). The accuracy increased to $75-100 \%$ per sampling location, with a mean of $89 \%$ when Sr isotopic data were combined with elemental data (Table 2). The accuracy for OKW increased by 20 to $85 \%$, and the highest accuracy was $100 \%$ for TKS (which corresponded to the findings for the elemental data only) and ISD.

\section{DISCUSSION}

We evaluated the applicability of the use of a suite of otolith elemental and isotopic compositions as a natal

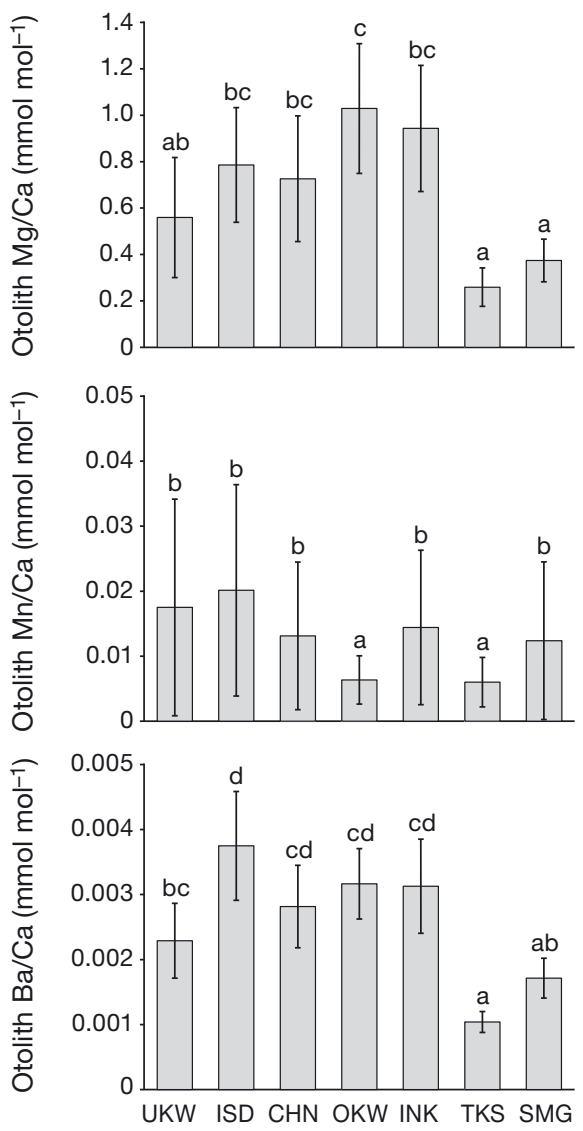

Fig. 4. Oncorhynchus masou subsp. Elemental and isotopic ratios (mean $\pm \mathrm{SD}$ ) of the otoliths of fish collected from 7 sampling locations. Statistical differences are shown with different letters. Post hoc multiple comparisons were performed using Steel-Dwass tests $(p<0.01)$. Location codes are shown in Table 1

tag for Biwa salmon in the Lake Biwa water system. Significant variations in otolith elemental composition and $\mathrm{Sr}$ isotopic ratios were detected among the 7 sampling locations. Combined analysis of elemental composition and $\mathrm{Sr}$ isotopic ratio could successfully associate individual fish with each sampling location with a high level of accuracy (mean $89 \%$ ). High variability in otolith chemistry based on geographical differences in habitat location has been reported for several freshwater fish species (Gibson-Reinemer et al. 2009, Pangle et al. 2010, Zeigler \& Whitledge 2011). If otolith chemistry can determine the natal or nursery area of an individual fish, it could also reveal the early dispersal patterns of fish in later stages of life. Furthermore, the movement of fish on a fine spatial scale may be traced when movement among locations is common (Campana 1999, Thorrold et al. 2001, Elsdon et al. 2008). 

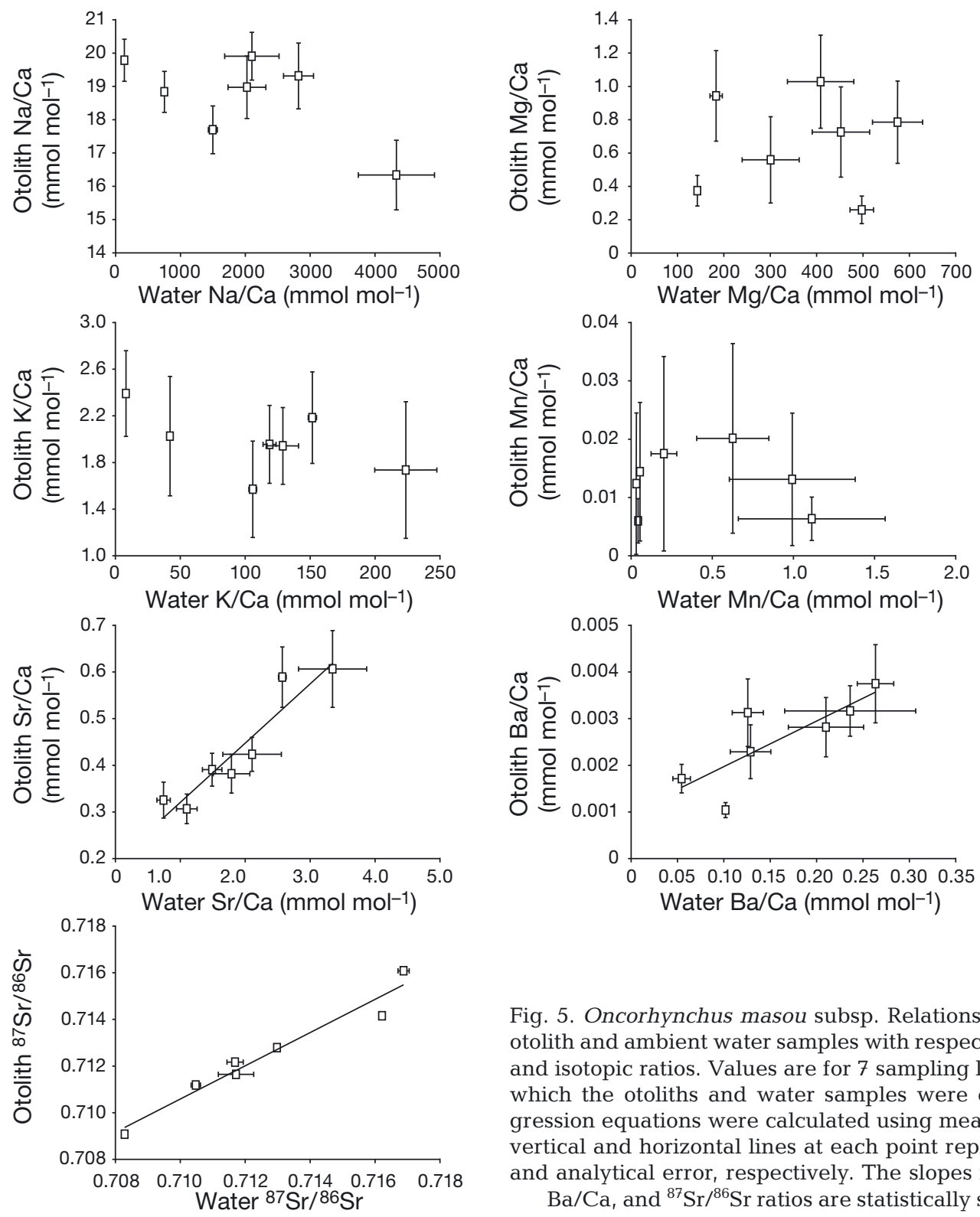

Fig. 5. Oncorhynchus masou subsp. Relationships between otolith and ambient water samples with respect to elemental and isotopic ratios. Values are for 7 sampling locations from which the otoliths and water samples were collected. Regression equations were calculated using mean values. The vertical and horizontal lines at each point represent the SD and analytical error, respectively. The slopes for the Sr/Ca, $\mathrm{Ba} / \mathrm{Ca}$, and ${ }^{87} \mathrm{Sr} /{ }^{86} \mathrm{Sr}$ ratios are statistically significant

Table 2. Cross-validated classification rates (\%) for quadratic discriminant function analysis assigned to sampling locations using otolith elemental data only as well as both elemental and Sr isotopic data

\begin{tabular}{|llcc|}
\hline No. & Location & $\begin{array}{c}\text { Elemental } \\
\text { data only }\end{array}$ & $\begin{array}{c}\text { Elemental and } \\
\text { isotopic data }\end{array}$ \\
\hline 1 & UKW & 80 & 85 \\
2 & ISD & 90 & 100 \\
3 & CHN & 60 & 75 \\
4 & OKW & 65 & 85 \\
5 & INK & 80 & 85 \\
6 & TKS & 100 & 100 \\
7 & SMG & 80 & 95 \\
& Average & 79 & 89 \\
\hline
\end{tabular}

Significant variations in otolith elemental and $\mathrm{Sr}$ isotopic compositions were found in juvenile Biwa salmon from different rivers and hatcheries from the north basin of Lake Biwa. Large differences between ISD and TKS fish were detected with very high assignment accuracy, although these locations are adjoining and only approximately $10 \mathrm{~km}$ a part (Fig. 1). Such a marked variation in otolith chemistry between individuals separated on a small scale has also been reported in Chinook salmon Oncorhynchus tshawytscha from California's Central Valley, USA (Barnett-Johnson \& Pearson 2008), brown trout Salmo trutta fario and rainbow trout $O$. mykiss in southern Austria (Zitek et al. 2010), rainbow smelt Osmerus 
mordax in southeastern Newfoundland, Canada (Bradbury et al. 2011), and the westslope cutthroat trout $O$. clarkii lewisi in Montana, USA (Muhlfeld et al. 2012). In those studies, the discrimination ability was increased by the variability in the ${ }^{87} \mathrm{Sr} /{ }^{86} \mathrm{Sr}$ ratio. In the present study, the $65 \%$ assignment accuracy for OKW fish rose to $85 \%$ when elemental data were combined with ${ }^{87} \mathrm{Sr} /{ }^{86} \mathrm{Sr}$ data. Because the otolith ${ }^{87} \mathrm{Sr} /{ }^{86} \mathrm{Sr}$ ratio is determined by the ratio in the ambient water, which itself reflects geological characteristics such as the age and composition of ${ }^{87} \mathrm{Rb}$, the otolith ratio in the fish should vary if the geological characteristics of their habitat waters are different (Kennedy et al. 1997, 2000, Ingram \& Weber 1999, Amakawa et al. 2012). Nakano et al. (2008) reported that the ${ }^{87} \mathrm{Sr} /{ }^{86} \mathrm{Sr}$ ratio of water varied markedly among rivers in Lake Biwa system. Therefore, the variability of the otolith ${ }^{87} \mathrm{Sr} /{ }^{86} \mathrm{Sr}$ in juvenile Biwa salmon provides a basis for the use of otoliths as archives for determining the history of the habitat use by individual fish, including natal locations.

We found that elemental composition could also discriminate the sampling locations for individual fish with a high level of accuracy similar to that based on the data combined with ${ }^{87} \mathrm{Sr} /{ }^{86} \mathrm{Sr}$ ratios. Previous studies have shown that spatial differences in otolith elemental compositions are significant in several freshwater species (Thorrold et al. 1998, Morris et al. 2003, Brazner et al. 2004). Variations in otolith elemental composition seem to be caused by physiological factors such as growth, maturation, and feeding (Kalish 1989, Otake et al. 1994, Chittaro et al. 2006) as well as environmental factors such as temperature, salinity, and the chemical composition of the ambient water (Elsdon et al. 2008). The significant differences in otolith elemental composition of juvenile Biwa salmon may derive mostly from the significant differences in water chemistry because significant correlations in $\mathrm{Sr} / \mathrm{Ca}$ and $\mathrm{Ba} / \mathrm{Ca}$ were found between the otoliths and water samples. A difference in ambient water temperature during the period from autumn to late spring in the freshwater regions of each river, where juvenile Biwa salmon develop, may also contribute to the variation in otolith chemistry. The average water temperature from October 2009 to May 2010 ranged from $9.1^{\circ} \mathrm{C}$ in ICD to $11.7^{\circ} \mathrm{C}$ in INK (Lake Biwa Environmental Research Institute, www. lberi.jp/root/jp/bkjhindex.htm). Presumably, these factors interact to make otolith chemical composition a practical natural tag for identifying habitat, including the natal rivers of each fish. However, the mechanism of elemental deposition in otoliths remains unknown. Further chemical and physiological studies are required to advance our understanding in this regard.

Our study findings suggest that otolith chemical signatures might be able to be used to trace the migration history of Biwa salmon across their entire life span. Previous studies have suggested that juvenile Biwa salmon develop in Lake Biwa until they mature (Fujioka \& Fushiki 1988). However, little is known about the distribution patterns and movements of the fish in the lake. Moreover, the rate of homing in mature Biwa salmon is unknown. These phenomena, both of which are important for understanding the life history strategy and establishing effective policies for conservation of Biwa salmon, could be successfully examined using the otolith microanalysis techniques that have been developed recently. Two approaches are possible: (1) using a micromill to obtain small amounts of material from otoliths to analyze their elemental and isotopic composition by TIMS or solution-based multi-collector ICP-MS (MC-ICP-MS; Kennedy et al. 2002, Arslan $\&$ Secor 2008) and (2) analyzing the elemental and isotopic composition using laser ablation ICP-MS or laser ablation MC-ICP-MS with a high spatial resolution ranging from 10 to several tens of micrometers in diameter (Milton \& Chenery 2003, Hamann \& Kennedy 2012, Muhlfeld et al. 2012). Using these techniques to analyze otoliths along the growth axis at an appropriate spatial resolution will provide information on chronological changes in otolith elemental and isotopic composition with a high time resolution, which will enable tracking of the movements of individual fish over their entire life span. Martin et al. (2013) used a laser ablation ICP-MS technique for otolith elemental ( $\mathrm{Sr} / \mathrm{Ca}$ and $\mathrm{Ba} / \mathrm{Ca}$ ) and $\mathrm{Sr}$ isotope ratios of Atlantic salmon Salmo salar. They found that QDFA was about $80 \%$ successful at classifying juveniles according to their natal rivers, which was a similar level to the present study. They could also successfully assign adults of unknown natal origin to their natal rivers using juvenile fingerprints from the QDFA approach.

Our study demonstrated that otolith elemental and Sr isotopic composition could accurately assign juvenile Biwa salmon to a sampling location, indicating that otolith chemistry has great potential as a tool for determining natal locations. Such a natal tag could reveal the migration history and habitat use of the species in Lake Biwa as well as provide information on the homing of matured fish that will aid the establishment of an effective fishery management strategy and policy for Biwa salmon, which is an important endemic subspecies in Lake Biwa. 
Acknowledgements. We thank the Shiga-Prefecture Samegai Trout Farm and M. Kobayashi of the Shiga-Prefecture Federation of Fishermen's Co-operative Association, for supplying the specimens and for other valuable information. We also thank K. Yokouchi and K. Kaifu for their critical and helpful comments on the draft of this manuscript. We are also grateful to M. J. Miller and Enago (www.enago.jp) for reviewing the use of English in the manuscript. This study was supported in part by a Grant-in-Aid for Scientific Research (Nos. 21380122 and 24380105, P.I.: T.O.) from the Ministry of Education, Culture, Sports, Science, and Technology, Japan, and by support from the Collaborative Research Project of the Lake Biwa Museum fund (Kyo 11-05).

\section{LITERATURE CITED}

- Amakawa H, Suzuki T, Takahashi T, Tatsumi Y, Otake T (2012) Sr isotopic compositions of ayu otolith and its ambient water. Fish Sci 78:1023-1029

- Arslan Z, Secor DH (2008) High resolution micromill sampling for analysis of fish otoliths by ICP-MS: effects of sampling and specimen preparation on trace element fingerprints. Mar Environ Res 66:364-371

> Ashford JR, Jones CM, Hofmann E, Everson I, Moreno C, Duhamel G, Williams R (2005) Can otolith elemental signatures record the capture site of Patagonian toothfish (Dissostichus eleginoides), a fully marine fish in the Southern Ocean? Can J Fish Aquat Sci 62:2832-2840

> Barnett-Johnson R, Pearson TE (2008) Tracking natal origins of salmon using isotopes, otoliths and landscape geology. Limnol Oceanogr 53:1633-1642

> Bath Martin G, Thorrold SR (2005) Temperature and salinity effect on magnesium, manganese, and barium incorporation in otoliths of larval and early juvenile spot Leiostomus xanthurus. Mar Ecol Prog Ser 293:223-232

> Bradbury IR, DiBacco C, Thorrold SR, Snelgrove PVR, Campana SE (2011) Resolving natal tags using otolith geochemistry in an estuarine fish, rainbow smelt Osmerus mordax. Mar Ecol Prog Ser 433:195-204

- Brazner JC, Campana SE, Tanner DK (2004) Habitat fingerprints for Lake Superior coastal wetlands from elemental analysis of yellow perch otoliths. Trans Am Fish Soc 133: 692-704

> Campana SE (1999) Chemistry and composition of fish otoliths: pathways, mechanisms and applications. Mar Ecol Prog Ser 188:263-297

> Campana SE, Thorrold SR (2001) Otoliths, increments, and elements: keys to a comprehensive understanding of fish populations? Can J Fish Aquat Sci 58:30-38

- Campana SE, Fowler AJ, Jones CM (1994) Otolith elemental fingerprinting for stock identification of Atlantic cod Gadus morhua using laser ablation ICPMS. Can J Fish Aquat Sci 51:1942-1950

- Chittaro PM, Hogan JD, Gagnon J, Fryer BJ, Sale PF (2006) In situ experiment of ontogenic variability in the otolith chemistry of Stegastes partitus. Mar Biol 149:1227-1235

- Elsdon TS, Gillanders BM (2002) Interactive effects of temperature and salinity on otolith chemistry: challenges for determining environmental histories of fish. Can J Fish Aquat Sci 59:1796-1808

Elsdon TS, Wells BK, Campana SE, Gillanders BM and others (2008) Otolith chemistry to describe movements and life-history parameters of fishes: hypotheses, assumptions, limitations and inferences. Oceanogr Mar
Biol Annu Rev 46:297-330

Fodrie FJ, Herzka SZ (2008) Tracking juvenile fish movement and nursery contribution within arid coastal embayments via otolith microchemistry. Mar Ecol Prog Ser 361:253-265

Fowler AJ, Campana SE, Jones CM, Thorrold SR (1995) Experimental assessment of the effect of temperature and salinity on elemental composition of otoliths using laser ablation ICPMS. Can J Fish Aquat Sci 52:1431-1441

Fujioka Y (1990) Biwa salmon: its ecological and morphological characteristics. Sakana To Ran 159:25-38 (in Japanese)

Fujioka Y, Fushiki S (1988) Downstream migration and body silvering in underyearling Biwa salmon Oncorhynchus rhodurus. Bull Jpn Soc Sci Fish 54:1889-1897

Furukawa T (1989) Biwamasu: Oncorhynchus masou subsp. In: Kawanabe K, Mizuno N (eds) Freshwater fishes of Japan. Yamakei, Tokyo, p 180-181 (in Japanese)

Gibson-Reinemer DK, Johnson BM, Martinez PJ, Winkelman DL, Koenig AE, Woodhead JD (2009) Elemental signatures in otoliths of hatchery rainbow trout (Oncorhynchus mykiss): distinctiveness and utility for detecting origins and movement. Can J Fish Aquat Sci 66:513-524

Gwo JC, Hsu TH, Lin KH, Chou YC (2008) Genetic relationship among four subspecies of cherry salmon (Oncorhynchus masou) inferred using AFLP. Mol Phylogenet Evol 48:776-781

> Hamann EJ, Kennedy BP (2012) Juvenile dispersal affects straying behaviors of adults in a migratory population. Ecology 93:733-740

Hendry AP, Castric V, Kinnison MT, Quinn TP (2004) The evolution of philopatry and dispersal: homing versus straying in salmonids. Oxford University Press, Oxford

Horreo JL, Hoz J, Pola IG, Machado-Schiaffino G, GarciaVazquez E (2012) Ecological and economic costs of supportive breeding: Atlantic salmon (Salmo salar) as a case study. Aquaculture 356-357:1-6

> Ingram BL, Weber PK (1999) Salmon origin in California's Sacramento-San Joaquin river system as determined by otolith strontium isotopic composition. Geology 27:851-854

Kalish JM (1989) Otolith microchemistry: validation of the effects of physiology, age and environment on otolith composition. J Exp Mar Biol Ecol 132:151-178

Kato F (1978) Morphological and ecological studies on two forms of Oncorhynchus rhodurus found in Lake Biwa and adjoining inlets. Jpn J Ichthyol 25:197-204

> Kennedy BP, Folt CL, Blum JD, Chamberlain CP (1997) Natural isotope markers in salmon. Nature 387:766-767

Kennedy BP, Blum JD, Folt CL, Nislow KH (2000) Using natural strontium isotopic signatures as fish markers: methodology and application. Can J Fish Aquat Sci 57:2280-2292

> Kennedy BP, Klaue A, Blum JD, Folt CL, Nislow KH (2002) Reconstructing the lives of fish using $\mathrm{Sr}$ isotopes in otoliths. Can J Fish Aquat Sci 59:925-929

Kimura S (1990) On the type specimens of Salmo macrostoma, Oncorhynchus ishikawae and O. rhodurus. Bull Inst Zool Acad Sin 29(Suppl):1-16

Kuwahara M, Iguchi K (1994) Occurrence of mature stream resident males of Biwa salmon, Oncorhynchus masou subsp. Jpn J Ichthyol 40:495-497

Kuwahara M, Iguchi K (2007) Occurrence of summer upstream migration in Biwa salmon (Oncorhynchus masou subsp.). Jpn J Ichthyol 54:15-20

Martin J, Bareille G, Berail S, Pécheyran C and others (2013) 
Persistence of a southern Atlantic salmon population: diversity of natal origins from otolith elemental and $\mathrm{Sr}$ isotopic signatures. Can J Fish Aquat Sci 70:182-197

McCraney WT, Farley EV, Kondzela CM, Naydenko SV, Starovoytov AN, Guyon JR (2012) Genetic stock identification of overwintering chum salmon in the North Pacific Ocean. Environ Biol Fishes 94:663-668

Milton DA, Chenery SR (2003) Movement patterns of the tropical shad hilsa (Tenualosa ilisha) inferred from transects of ${ }^{87} \mathrm{Sr} /{ }^{86} \mathrm{Sr}$ isotope ratios in their otoliths. Can J Fish Aquat Sci 60:1376-1385

Morris JA, Rulifson RA, Toburen LH (2003) Life history strategies of striped bass, Morone saxatilis, populations inferred from otolith microchemistry. Fish Res 62:53-63

Muhlfeld CC, Thorrold SR, Mcmahon TE, Marotz B (2012) Estimating westslope cutthroat trout (Oncorhynchus clarkii lewisi) movements in a river network using strontium isoscapes. Can J Fish Aquat Sci 69:906-915

Nakano T, Tayasu I, Yamada Y, Hosono T and others (2008) Effect of agriculture on water quality of Lake Biwa tributaries, Japan. Sci Total Environ 389:132-148

Oda M, Akiba K, Yamamoto T (2008a) Natural reproduction of Biwa salmon Oncorhynchus masou subsp. in an inlet stream of Lake Biwa, central Japan. Biol Inland Waters 23:1-6

Oda M, Akiba K, Yamamoto T (2008b) The habit of Biwa salmon Oncorhynchus masou subsp. in swim-up period of fry. Biol Inland Waters 23:7-14

Oda M, Kishino T, Harada Y (2011) Body size at maturity of Biwa salmon Oncorhynchus masou subsp. in some inlet rivers of Lake Biwa, central Japan. Jpn J Ichthyol 58: 171-175

> Oohara I, Okazaki T (1996) Genetic relationship among three subspecies of Oncorhynchus masou determined by mitochondrial DNA sequence analysis. Zoolog Sci 13: 189-198

Otake T, Ishii T, Nakahara M, Nakamura R (1994) Drastic changes in otolith strontium/calcium ratios in leptocephali and glass eels of Japanese eel Anguilla japonica. Mar Ecol Prog Ser 112:189-193

> Pangle KL, Ludsin SA, Fryer BJ (2010) Otolith microchemistry as a stock identification tool for freshwater fishes: testing its limits in Lake Erie. Can J Fish Aquat Sci 67: 1475-1489

Patterson HM, McBride RS, Julien N (2004) Population structure of red drum (Sciaenops ocellatus) as determined by otolith chemistry. Mar Biol 144:855-862

Secor DH, Rooker JR, Zlokovitz E, Zdanowicz VS (2001) Identification of riverine, estuarine, and coastal contingents of Hudson River striped bass based upon otolith elemental fingerprints. Mar Ecol Prog Ser 211:245-253

Shirai K, Takahata N, Yamamoto H, Omata T, Sasaki T, Sano Y (2008) Novel analytical approach to bivalve shell bio-

Editorial responsibility: Christine Paetzold, Oldendorf/Luhe, Germany geochemistry: a case study of hydrothermal mussel shell. Geochem J 42:413-420

Takahashi T, Yoshikawa M, Shibata T, Tatsumi Y, Shimizu N (2006) Sr isotopic micro-analyses of plagioclase in andesites from Zao volcano, NE Japan. Front Res Earth Evol 2:1-5

> Takahashi T, Hirahara Y, Miyazaki T, Vaglarov BS, Chang Q, Kimura J, Tatsumi Y (2009) Precise determination of Sr isotope ratios in igneous rock samples and application to micro-analysis of plagioclase phenocrysts. JAMSTEC Rep Res Dev 2009:59-64

Thorrold SR, Jones CM, Campana SE, McLaren JW, Lam JWH (1998) Trace element signatures in otoliths record natal river of juvenile American shad (Alosa sapidissima). Limnol Oceanogr 43:1826-1835

Thorrold SR, Latkoczy C, Swart PK, Jones CM (2001) Natal homing in a marine fish metapopulation. Science 291: 297-299

Townsend DW, Radtke RL, Corwin S, Libby DA (1992) Strontium:calcium ratios in juvenile Atlantic herring Clupea harengus L. otoliths as a function of water temperature. J Exp Mar Biol Ecol 160:131-140

> Tunheng A, Hirata T (2004) Development of signal smoothing device for precise elemental analysis using laser ablation-ICP-mass spectrometry. J Anal At Spectrom 19:932-934

Walther BD, Thorrold SR (2008a) Geochemical signatures in otoliths record natal origins of American shad. Trans Am Fish Soc 137:57-59

Walther BD, Thorrold SR (2008b) Continental-scale variation in otolith geochemistry of juvenile American shad (Alosa sapidissima). Can J Fish Aquat Sci 65:2623-2635

Yamane K, Shirai K, Nagakura Y, Yamaguchi M and others (2010) Spatial variation in otolith elemental composition of the Pacific herring Clupea pallasii in northern Japan. Aquat Biol 10:283-290

Yamane K, Shirai K, Nagakura Y, Otake T (2012) Assessing the usefulness of otolith elemental compositions for evaluating the population structure of the Pacific herring Clupea pallasii in northern Japan. Fish Sci 78:295-307

Yokouchi K, Fukuda N, Shirai K, Aoyama J, Daverat F, Tsukamoto K (2011) Time lag of the response on the otolith strontium/calcium ratios of the Japanese eel, Anguilla japonica to changes in strontium/calcium ratios of ambient water. Environ Biol Fishes 92:469-478

Zeigler JM, Whitledge GW (2011) Otolith trace element and stable isotopic compositions differentiate fishes from the Middle Mississippi River, its tributaries, and floodplain lakes. Hydrobiologia 661:289-302

Zitek A, Sturm M, Waidbacher H, Prohaska T (2010) Discrimination of wild and hatchery trout by natural chronological patterns of elements and isotopes in otoliths using LA-ICP-MS. Fish Manag Ecol 17:435-445

Submitted: Febuary 11, 2013; Accepted: July 3, 2013

Proofs received from author(s): August 20, 2013 